\title{
SHANGHAI SHORELINE EVOLUTION INTERPRETED FROM HISTORICAL ATLAS AND REMOTE SENSING IMAGERY OVER THE PAST 2,200 YEARS
}

\author{
H. Mi ${ }^{\mathrm{a}, \mathrm{b}}$, W. Wang ${ }^{\mathrm{a}, \mathrm{b}}$, G. Qiao ${ }^{\mathrm{a}, \mathrm{b}, *}$ \\ ${ }^{a}$ College of Surveying and Geo-Informatics, Tongji University, 1239 Siping Road, Shanghai, China \\ ${ }^{\mathrm{b}}$ Center for Spatial Information Science and Sustainable Development, Tongji University, 1239 Siping Road, Shanghai, China
}

Commission VIII, WG VIII/9

KEY WORDS: Shanghai, Shoreline Change, Evolution, Atlas, Remote Sensing

\begin{abstract}
:
Shanghai, the axis of economic development in China and holding the most prosperous metropolis in the world, is located at Yangtze Estuary which is susceptible to shoreline changes affected by different factors, such as sediment supply and sea level changes, making it very important to study the shoreline changes over long time period. This paper presents the Shanghai shoreline evolution process from BC 221 up to 2015, by employing both the cartographic data (historical atlas) and the remote sensing images. A series of image processing techniques were applied to seamlessly register the historical atlas and satellite images to the same orthophoto base map, followed by the semi-automatic extraction of shoreline from images. Results show that since BC 221 , the Shanghai shoreline has been witnessing distinct progradation, and the rate of shoreline advance varied in different areas. The average shoreline change in southern Yangtze Estuary was about 2,573 km² (accretion) between BC 221 and 1948 with a $40 \mathrm{~km}$ progradation, while the shoreline in northern Hangzhou Bay kept relatively steady after 1671 . Overall, $3,119 \mathrm{~km}^{2}$ of Shanghai area was added between BC 221 and 1948 with an average rate of $75 \mathrm{~km}^{2} / 50 \mathrm{yr}$, and the addition went to $4,372 \mathrm{~km}^{2}$ in 2015 . In this paper, the possible drives of the shoreline evolution was discussed. This study is important for understanding the coastal dynamics in Shanghai over a long time period for the management and development of coastal environments.
\end{abstract}

\section{INTRODUCTION}

Global mean sea-level change has increased in the rate of rise due to climate change through the melting of land ice and the thermal expansion of ocean water (Milne et al., 2009; Nicholls et al., 2010). Rapid sea-level rise seriously threatens the estuaries and islands, where a large percentage of the population lives (Anthoff et al., 2006; Nicholls et al., 2010; Johnston et al., 2014; Kunt et al., 2014). So, coastal zone monitoring becomes an important task in national development and environmental protection (Rasuly et al., 2010). Shoreline, one of the coastal zone features recognized by International Geographic Data Committee (Kuleli et al., 2011), is valuable for coastal monitoring and assessment (Marfai et al., 2008). The location of the shoreline and its historical rate of change can provide important information for the design of coastal protection, plans for coastal development (Chen et al., 2009).

Shanghai, the axis of economic development in China and holding the most prosperous metropolis in the world, is located at Yangtze Estuary which is susceptible to shoreline changes affected by different factors, such as sediment supply and sea level changes, making it very important to study the shoreline changes over long time period. In this paper, we presents the Shanghai shoreline evolution process from BC 221 up to 2015, by employing both the fifteen-period cartographic data (historical atlas) spanning from BC221 to 1948 and the twelveperiod remote sensing images from 1960 to 2015. Section 2 introduces the study area and data, including the image processing; Section 3 analyses the shoreline evolution; Section
4 discusses the possible drives of the shoreline change; and last Section gives the conclusion.

\section{STUDY AREA AND DATA}

\subsection{Study area}

Shanghai stands at $120^{\circ} 51^{\prime} \mathrm{E}$ to $122^{\circ} 12^{\prime} \mathrm{E}$ and $30^{\circ} 40^{\prime} \mathrm{N}$ to $31^{\circ} 53^{\prime} \mathrm{N}$ (Figure 1), on the western coast of the East Sea and the eastern shoreline of the Asian Continent, with Yangtze River to its north, and Hangzhou Bay to its south. There are several delta islands, such as Chongming Island, Changxing Island and Hengsha Island. Shanghai, with about $6340 \mathrm{~km}^{2}$ area, has more than 24 million permanent residents in 2015 (Office of Shanghai Chronicles, 2015).

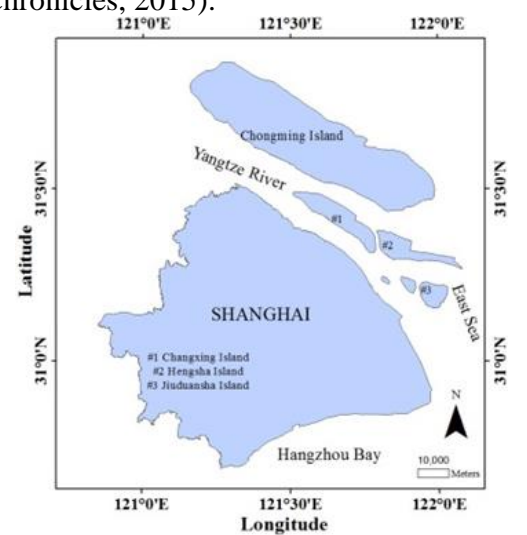

Figure 1. Location map of Shanghai, China

\footnotetext{
* Corresponding author
} 


\subsection{Data and Image Processing}

2.2.1 Data: This paper utilized the Shanghai historical atlas edited by Zhou (1999) as the basis of historical data to study the Shanghai shoreline evolution process from BC 221 up to 1948. The fifteen-period cartographic data (historical atlas) were used in this research, and the specific time includes BC 221, 140, 282, 582, 546, 612, 751, 954, 1111, 1217,1660, 1617, 1756, 1866, 1944, 1948. All atlas based on administrative map of 1999 to represent relative locations. The Shanghai historical atlas in BC 221 is given as an example and shown in Figure 2 (a).

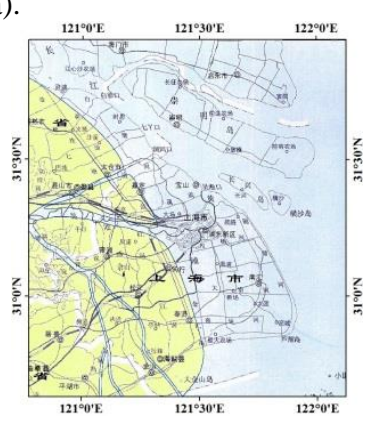

(a)

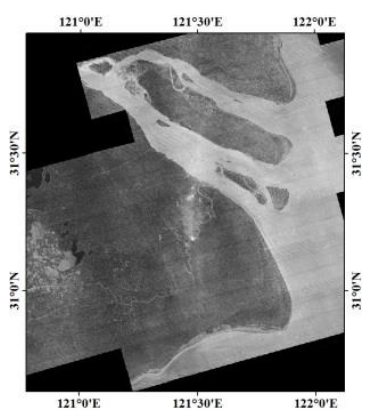

(b)
Figure 2. Selected examples of Shanghai historical atla and DISP image. (a) atlas in BC 221; (b) DISP image in 1960

Remote sensing, as an important means, is widely employed in shoreline change research. The Declassified Intelligence Satellite Photographs (DISP) obtained by US since 1960s is of great significance for monitoring shoreline changes. Besides, Shanghai was also covered by a large number of available Landsat images since Landsat launched. The remote sensing images applied in this research contain the declassified filmbased CORONA satellite images from 1960 to 1980, and the Landsat images from 1985 to 2015, at a five-year time interval. Figure 2 (b) shows an example of the DISP images (in 1960).

2.2.2 Image Processing: The Shanghai historical atlas were first digitalized and geometrically rectified and registered to a SOPT-image derived orthophoto that was used as a base map, and then the shorelines at each period was extracted and overlaid together. A series of image processing techniques were applied to seamlessly register the satellite images to the same orthophoto base map, followed by the semi-automatic extraction of shoreline from images. All the twenty-seven shorelines are overlaid and shown in Figure 3 .

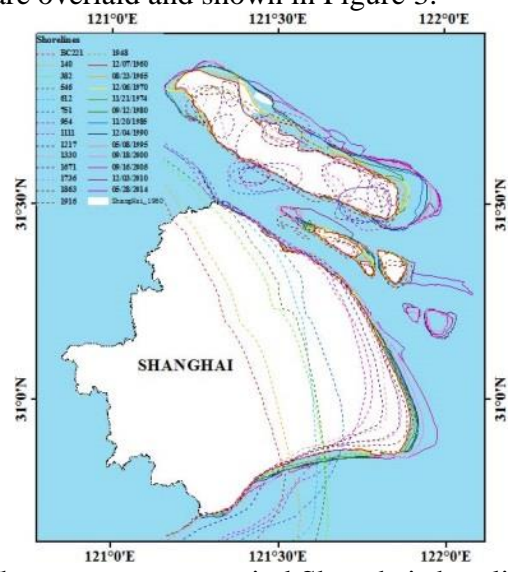

Figure 3. The twenty-seven period Shanghai shorelines over the past 2,200 years generated from historical atlas (from BC221 to

1948) and remote sensing images (from 1960 to 2015)

\section{SHORELINE CHANGE ANALYSIS}

Accumulation of area variation for Shanghai is presented in Figure 4. Results indicate that since BC 221, the Shanghai shoreline has been witnessing distinct progradation. Overall, $3,119 \mathrm{~km}^{2}$ of Shanghai area was added between BC 221 and 1948 with an average rate of $75 \mathrm{~km}^{2} / 50 \mathrm{yr}$, and the addition went to $4,372 \mathrm{~km}^{2}$ in 2015 .

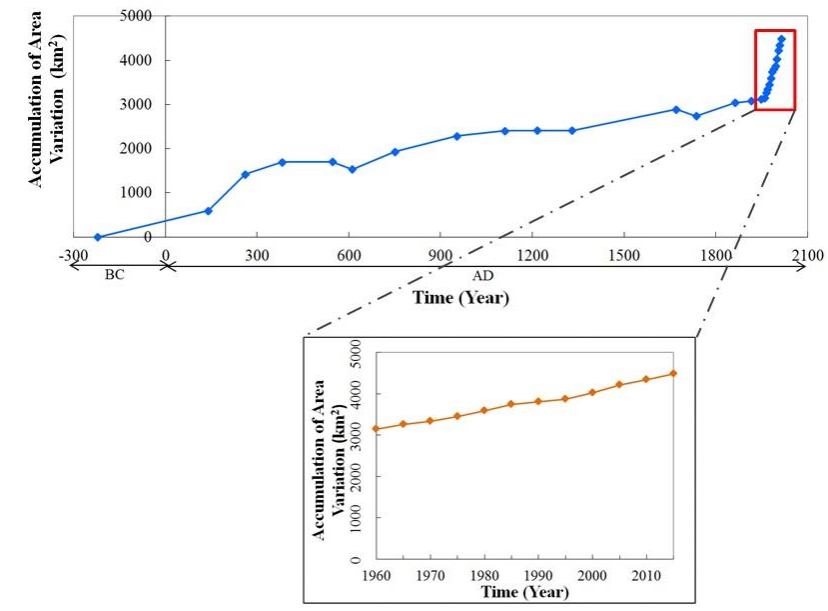

Figure 4. Accumulation of area variation for Shanghai

The rate of Shanghai shoreline advance varied in different areas. The average shoreline change in southern Yangtze Estuary was about 2,573 $\mathrm{km}^{2}$ (accretion) between BC 221 and 1948 with a $40 \mathrm{~km}$ progradation, while the shoreline in northern Hangzhou Bay kept relatively steady after 1671 (Figure 5).

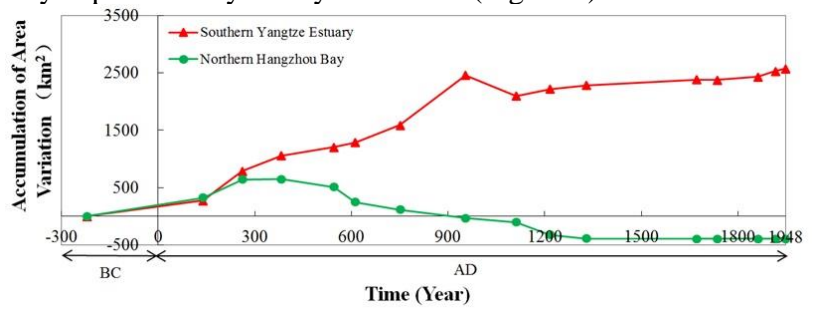

Figure 5. Accumulation of area variation in southern Yangtze Estuary and northern Hangzhou Bay

\section{DRIVING FORCES OF SHORELINE CHANGE}

Shoreline change in Shanghai has been largely driven by natural condition and anthropogenic modification of the coastal system since 1960 . In this section, we will briefly analyse some driving forces of shoreline change.

\subsection{Sediment}

Shanghai is located at the confluence of the Yangtze River and the Qiantang River, where siltation or erosion is under the influence of sediment (Xie et al., 2002). Figure 6 shows the yearly changes of water and sediment discharge at the Datong gauging station on the Yangtze River. Since 1960's, sediment discharge values have shown a significant reduction, due to human activities especially the Three Gorges Dam, which went into operation in 2003 (Yang et al., 2005; Li et al., 2014). The effect of this reduction on the deltaic coast is also obvious. 


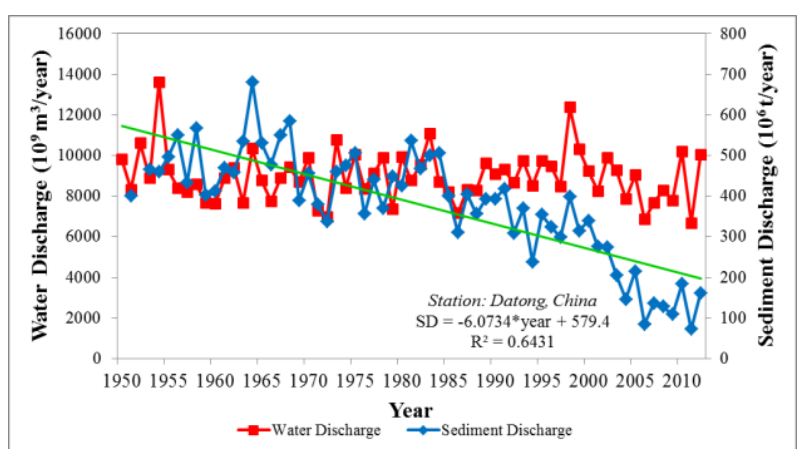

Figure 6. Yearly changes of water and sediment discharge at the Datong gauging station

\subsection{Waterway Engineering}

The Yangtze River estuary is characterized by four branches of tidal channels and three major bifurcations. The North and South Branches are separated by Chongming Island. The South Branch is further divided into the South Channel and North Channel. The South Channel is again divided into the North Passage and South Passage, as shown in Figure 7. Shipping is a significant contributor to Shanghai's development, and waterway engineering in these regions also influence the shoreline evolution.

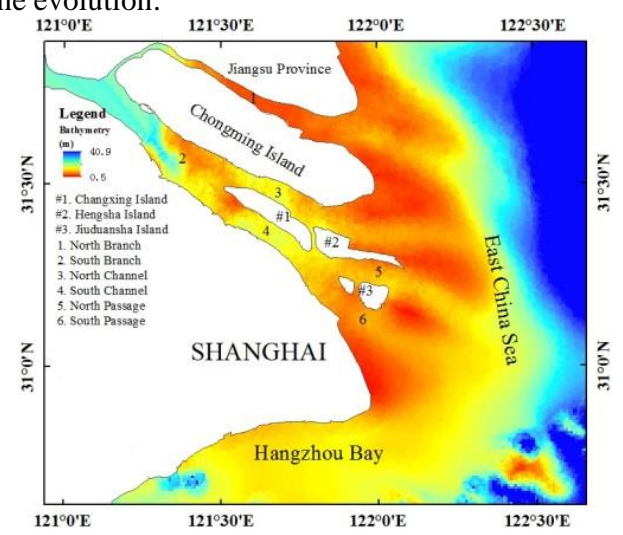

Figure 7. Bathymetric map and channel structure of the Yangtze Estuary

\subsection{Reclamation}

The accelerating rate of urbanization in Shanghai, needs everincreasing amounts of land for urban and socio-economic development (Wang et al., 2014; Cui et al., 2015). According to the reports of Shanghai Water Authority, a total $1040.9 \mathrm{~km}^{2}$ of the coastal wetlands in the Yangtze Estuary have been reclaimed in the period 1949-2010 (Shanghai Water Authority, 2010). This large-scale reclamation has accelerated the shoreline change.

\section{CONCLUSION}

This paper presents the Shanghai shoreline evolution process from BC 221 up to 2015, by employing both the fifteen-period cartographic data (historical atlas) spanning from BC221 to 1948 and the twelve-period remote sensing images from 1960 to 2015. Over the past 2,200 years, the Shanghai shoreline has been witnessing distinct progradation, predominantly due to sediment supply from Yangtze River, and the rate of shoreline advance varied in different areas. The research work on shoreline evolution process and possible drives forces, is important for understanding the coastal dynamics in Shanghai over a long time period for the management and development of coastal environments

\section{ACKNOWLEDGEMENTS}

This research was supported by the State Key Development Program for Basic Research of China (2012CB957704, 2012CB957701), the National Science Foundation of China (91547210, 41201425), the China Special Fund for Surveying, Mapping and Geoinformation Research in the Public Interest (201412017), and the Fundamental Research Funds for the Central Universities.

\section{REFERENCES}

Anthoff, D., Nicholls, R.J., Tol, R.S.J., and Vafeidis, A.T., 2006. Global and regional exposure to large rises in sea-level: A sensitivity analysis. Tyndall Centre for Climate Change Research-Working Paper, 96.

Chen, W.W., and Chang, H.K., 2009. Estimation of shoreline position and change from satellite images considering tidal variation. Estuarine, Coastal and Shelf Science, 84(1), pp. 5460.

Cui, L., Ge, Z., Yuan, L., and Zhang, L., 2015. Estuarine , coastal and shelf science vulnerability assessment of the coastal wetlands in the Yangtze Estuary, China to sea-level rise. Estuarine, Coastal and Shelf Science, 156, pp. 42-51.

Johnston, A., Slovinsky, P., and Yates, K.L., 2014. Assessing the vulnerability of coastal infrastructure to sea level rise using multi-criteria analysis in Scarborough, Maine (USA). Ocean \& Coastal Management, 95, pp. 176-188.

Kunte, P.D., Jauhari, N., Mehrotra, U., Kotha, M., Hursthouse, A.S., and Gagnon, A.S., 2014. Multi-hazards coastal vulnerability assessment of Goa, India, using geospatial techniques. Ocean \& Coastal Management, 95, pp. 264-281..

Kuleli, T., Guneroglu, A., Karsli, F., and Dihkan, M., 2011. Automatic detection of shoreline change on Coastal Ramsar Wetlands of Turkey. Ocean Engineering, 38(10), pp. 11411149 .

Li, X., Zhou, Y., Zhang, L., and Kuang, R., 2014. Shoreline change of Chongming Dongtan and response to river sediment load: A remote sensing assessment. Journal of Hydrology, 511, pp. $432-442$

Milne, G.A., Gehrels, W.R., Hughes, C.W. and Tamisiea, M.E., 2009. Identifying the causes of sea-level change. Nature Geoscience, 2(7), pp. 471-478

Marfai, M.A., Almohammad, H., Dey, S., Susanto, B., and King, L., 2008. Coastal dynamic and shoreline mapping: Multisources spatial data analysis in Semarang Indonesia. Environmental Monitoring and Assessment, 142(1), PP. 297308 .

Nicholls, R.J., and Cazenave, A., 2010. Sea-level rise and its impact on coastal zones. Science, 328(5985), pp. 1517-1520

Office of Shanghai Chronicles, 2015. http://www.shtong.gov.cn. 
Rasuly, A., Naghdifar, R., and Rasoli, M., 2010. Monitoring of Caspian Sea coastline changes using object-oriented techniques. Procedia Environmental Sciences, 2, 416-426.

Shanghai Water Authority, 2010. Shanghai Foreshore Resources Report. Shanghai Water Authority, Shanghai (in Chinese).

Wang, H., Ge, Z., Yuan, L., and Zhang, L., 2014. Evaluation of the combined threat from sea-level rise and sedimentation reduction to the coastal wetlands in the Yangtze Estuary, China. Ecological Engineering, 71, 346-354.

Xie, D., Pan, C., Cao, Y., and Zhang, B., 2013. Decadal variations in the erosion/deposition pattern of the Hangzhou Bay and their mechanism in recent 50a. Acta Oceanologica Sinica, 35(4), pp. 121-128 (in Chinese).

Yang, S.L., Zhang, J., Zhu, J., Smith J.P., Dai, S.B., Gao, A., and Li, P., 2005. Impact of dams on Yangtze River sediment supply to the sea and delta intertidal wetland response. Journal of Geophysical Research: Earth Surface, 110.

Zhou, Z.H., 1999. The Shanghai historical atlas. 